\title{
Perspective
}

\section{Medicine and the Task of Healing}

\author{
Paul A. Komesaroff* \\ Centre for Ethics in Medicine and Society, Monash University, Melbourne, Australia
}

Received: 16 July 2013, Accepted: 7 August 2013, ePublished: 8 August 2013

\begin{abstract}
To understand the traditional description of medicine as a practice of healing, it is necessary to examine its relationships with both science and ethics. The "scientific" component of medicine includes an acknowledgment of the influence of social, cultural and environmental factors on the functioning of the organism. The "ethical" component is often presented as merely supplementary but actually provides the conditions of possibility of knowledge. "Healing" then appears as what joins the two together: the site where science is applied in the service of ethics and where ethics encounters science. This perspective allows us to reconsider medicine as a project to healing complex wounds that manifest themselves at the physical, psychological, emotional and cultural levels.
\end{abstract}

Keywords

Medicine, Ethics, Science, Healing

\section{Background}

One of the most ancient traditions of medicine in every culture is that it should be understood simply as a practice of healing. The simplicity of this proposition is however, deceptive, because it includes implicitly within its assumptions about fundamental concepts.

To understand why the idea of medicine at the service of healing is so difficult, it is necessary to reflect on the conceptual history of the varieties of medical practice. All of them incorporate in some manner two components, "science" and "ethics", the former deals with the current state of "knowledge" and the latter deals with the meanings and values associated with it.

\section{Science}

Over the epochs, the part of medicine that makes claims about "facts" has passed through many versions, related to the changing views of knowledge and truth. In all cases, the prevailing body of thought has been presented as "objectively" true and incontestable: that is, after all, the nature of all systems of science (1). In particular, since the late nineteenth century the dominant global paradigm of medicine has been linked directly to a mechanistic understanding of the body, first as an elaborate mechanical device and more recently as a feedback system with multiple degrees of freedom. This was later linked to a formal commitment to biological reductionism: that is, to the proposition that all physical phenomena can ultimately be explained within the discourse of contemporary biological science. There is nothing inherently "true" or "objective" about either of these assumptions: in fact, rival philosophical formulations-such as those of the traditional Chinese and Ayurvedic traditions-continue to be practised even today and to command substantial followings.

From both the mechanistic and the reductionist perspectives the body is seen as radically isolated from society, and it is assumed that any therapeutic intervention must be directed at its internal micro-functioning. From the mid-nineteenth century, this was already recognised as inadequate because it neglected the impact of the social and physical environments on biological functions. After all, with the Industrial Revolution and the development of mass society, the critical effects of living and working conditions on health and well-being had become starkly obvious. This was reinforced as the tools for social analysis began to mature and more refined analysis of the role of social variables on indices of disease became possible.

\section{Ethics}

The recognition of the crucial interplay between social experience and the outcomes of medicine raised questions not just in the scientific domain but also in that of ethics. From the beginning, doctors had followed codes of conduct that established the social basis for them to be granted privileged access to individual bodies that would otherwise be contrary to prevailing norms. However, the role of ethics had always gone deeper than this. It had always been taken for granted that medicine only existed because it served moral purposes. These purposes were formulated in different ways: alleviating suffering, restoring harmony, overcoming pathology or dysfunction; but ultimately it was in this domain that the values were defined that set the ultimate goals and meanings for the entire enterprise.

Medicine, therefore, was associated with ethics in two ways. As the understanding of its nature as a clinical practice was further extended within contemporary theory, however, it became apparent that there was a third, even more fundamental, manner in which the two were connected. Medicine is inherently ethical, not just because doctors have to follow codes of conduct or because ethical values hang off science but because ethics is the theoretical and practical condition of possibility of all medicine

ॠCorresponding author: Paul A. Komesaroff; Email: paul.komesaroff@monash.edu 
and science. The project of medicine itself, and the purposes it supposedly serves, only come into existence on the basis of a prior, irrevocable and primordial commitment to the other that forms the basis for the foundational concepts of value, morality and ethics, and therefore, of specific values such as trust, responsibility and respect (2).

Some theories of ethics purport to depart from the reductionist premise that medicine is a collection of facts to which "values" may subsequently be attributed. In reality, as I have argued, it is the other way round: it is ethics that is truly fundamental and generative and science only comes into existence because it provides a means for exploring and advancing the domain of values. Indeed, we can go further: the individuals who define the goals of medicine and science themselves only come into existence as conscious subjects as a secondary effect of the ethical bond that generates meaning and sense and makes language and the process of critical reflection possible. In this sense, ethics precedes consciousness, science and therefore even "matter".

Where then, do the common misconceptions come from? Once the two domains of ethics and science were established the logic of each took over. Despite their inherent and originary connection, science was seen to follow a set of discursive imperatives that were entirely internal to it, and ethics was understood to be explicable also only in its own terms. What's more, each was defined as a technical sphere accessible only to a limited number of experts. The indivisible unity of ethics and medicine was replaced by two distinct intellectual disciplines standing opposite, and in opposition, to each other.

\section{Healing}

If medicine and ethics are in fact inherently indivisible, where does healing come in? The answer is that healing is just what joins the two of them together: it is the suture of the wound that has rent them apart. Healing is the practical site where the knowledge of science is applied in the service of ethics, and where ethics encounters the conditions of science. It is directed towards overcoming pathology_-but pathology understood in the expanded sense that is required by contemporary knowledge.

Healing is not just directed towards rectifying disturbances in the structures of tissues. It can also encompass the effects of the social and environmental conditions on the body, and it can include physical, psychological and emotional functioning. It can include conventional causes of disease, such as infectious agents and malignancies. And it can cover the impact of the changing urban environment on the functioning of the organism. It can refer to the conditions of work, or of unemployment. It can encompass the impact of a damaged biosphere, and its internal meanings. It can refer to the effects of war, of revolution, of degraded social and political institutions, and of the loss of hope and meaning that is the inevitable outcome of prolonged social conflict.

In any particular nation or community, when we come to consider what are the wounds that need healing we need to examine the specific and local contextual conditions. In developed Western societies ageing and social breakdown, dementia, cancer, non-communicable diseases, obesity, drug addiction and violence have assumed special importance. In developing countries, concerns about infectious diseases, especially HIV and its profound social consequences, and the atrophy of traditional caring relationships with the transition to "modernity" may predominate. The tasks of the doctor and other health professionals have to be fashioned according to need, but have now also to be extended to include the full expanse of human suffering. Sometimes, this will mean that the doctor's life will be quiet and comfortable; sometimes it will require a degree of social activism; on rare occasions the circumstances will be such that the true practice of the craft will require courage and exposure to risk.

It remains the case today that medicine is a practice of healing, but this does not tell us what we as practitioners must do to realise the purposes of our profession. This, like the profession itself, is an unfinished task. For our own setting, our own community, our own country, we must address the questions: what are the wounds that are yet to be healed, and what is the role we ourselves must play in order to help them do so?

Ethical issues

Not applicable.

\section{Competing interests}

The author declares that he has no competing interests.

Author's contribution

PAK is the single author of the manuscript.

References

1. Komesaroff PA. Objectivity, science and society. London: Routledge; 2009.

2. Komesaroff PA. Experiments in love and death. Melbourne: Melbourne University Press; 2008. 